\title{
Reclassificação taxonômica de espécies do gênero Malassezia: revisão da literatura sobre as implicações clinicolaboratoriais
}

\author{
Reclassification of Malassezia species: a review of its clinical and laboratory significance
}

\author{
Fábio dos Santos Schlottfeldt ${ }^{1}$ \\ Sayonara Werner Tramontin \\ Berenice Pagani Nappi ${ }^{2}$ \\ Jairo Ivo dos Santos ${ }^{2}$
}

\begin{tabular}{l|l}
\multicolumn{1}{c|}{ unitermos } & resumo \\
Malassezia & $\begin{array}{l}\text { O gênero Malassezia compreende leveduras lipofílicas e lipodependentes que recentemente } \\
\text { saxonomia }\end{array}$ \\
$\begin{array}{l}\text { Pitiríase versicolor } \\
\text { Técnicas de diagnóstico }\end{array}$ & $\begin{array}{l}\text { espécies: M. globosa, M. obtusa, M. slooffiae e M. restricta, além das espécies M. furfur, M. } \\
\text { pachydermatis e M. sympodialis, já descritas. Estas leveduras estão associadas a vários quadros } \\
\text { patológicos que incluem infecções como a pitiríase versicolor ou dermatoses, como dermatite } \\
\text { seborréica e dermatite atópica, entre outros. Estes quadros eram, até pouco tempo atrás, } \\
\text { considerados devidos exclusivamente à espécie M. furfur. Estas mudanças na classificação } \\
\text { taxonômica de Malassezia levaram a uma reavaliação dos procedimentos laboratoriais que } \\
\text { eram utilizados para a identificação do agente etiológico. Entre eles podemos citar o estudo e } \\
\text { a caracterização morfológica das espécies, sua tolerância térmica, suas necessidades } \\
\text { nutricionais para determinados tipos de ácidos graxos, bem como a composição e as } \\
\text { características do DNA de cada uma delas. }\end{array}$
\end{tabular}

\section{abstract}

The genus Malassezia comprises lipophylic and lipodependent yeast species that recently suffered a change in their taxonomic classification, with the description of four new species: M. globosa,

M. obtusa, M. slooffiae and M. restricta besides the already described species M. furfur, M. pachydermatis and M. sympodialis. These yeasts are associated to pathologies that include tinea versicolor, seborrheic and atopic dermatitis, among others. These diseases were previously

thought to be exclusively due to the species M. furfur. The taxonomical changes observed for species of Malassezia genus has led to a reassessment of the laboratory methodologies that were formerly used for the identification of the etiologic agent. Morphologic and physiologic variations for each species, termo-tolerance, their requirements for certain long-chain fatty acid sources, as well the composition and characteristics of their DNA are among them. key words

Malassezia

Classification

Tinea versicolor

Diagnostic techniques 


\section{Introdução}

O gênero Malassezia, descrito originalmente por Baillon em 1889, compreende leveduras lipofílicas e lipodependentes que fazem parte da microbiota normal de seres humanos e de animais $(19,26)$.

Segundo Aspíroz et al. (2), o gênero Malassezia apresenta a seguinte classificação taxonômica:

- Reino: Fungi

- Filo: Deuteromycotina

- Classe: Blastomycetes

- Ordem: Cryptococcales

- Família: Cryptococcaceae

- Gênero: Malassezia

Até pouco tempo eram conhecidas apenas três espécies neste gênero: Malassezia furfur, M. pachydermatis e $M$. sympodialis. Desde então, quatro novas espécies foram descritas: $M$. globosa, M. obtusa, M. restricta e M. slooffiae (11).

\section{Diferenciação entre as espécies de Malassezia}

Embora as espécies de Malassezia sejam muito semeIhantes entre si, elas podem ser diferenciadas por meio de critérios morfofisiológicos $(11,13,20)$, nos quais são observadas as diferenças na micromorfologia de cada espécie, a atividade enzimática e suas necessidades nutricionais; e critérios moleculares, nos quais são avaliadas a composição e características do seu DNA $(4,12,14)$.

Para a diferenciação morfofisiológica das espécies de Malassezia, as mesmas são cultivadas em meio de Dixon modificado a $32^{\circ} \mathrm{C}$ durante sete dias. Nestas condições, as espécies apresentam as seguintes características morfológicas:

\section{M. furfur}

As colônias desta espécie apresentam textura cremosa, são friáveis, convexas e de coloração branco-fosco. No exame microscópico observam-se células de variados tamanhos e formas: ovais $(1,5 \mu \mathrm{m}-3 \mu \mathrm{m})$, cilíndricas $(2,5 \mu \mathrm{m}-8 \mu \mathrm{m})$ ou esféricas $(2,5 \mu \mathrm{m}-5 \mu \mathrm{m}$ de diâmetro). Os brotos são formados na base larga da célula, e os filamentos podem originar-se em qualquer ponto da levedura. Apresenta reação de catalase positiva. Cresce em presença de concentrações variadas de ácidos graxos de cadeia longa, incluindo ácido ricinoléico e seus derivados. A temperatura ótima para o crescimento é de $37^{\circ} \mathrm{C}$, embora também possa crescer em temperaturas de até $41^{\circ} \mathrm{C}$.

\section{M. pachydermatis}

Esta espécie é uma levedura zoofílica encontrada principalmente no conduto auditivo de várias espécies de animais, podendo, entretanto, ser isolada da pele de seres humanos. É um fungo lipofílico, porém não-lipodependente, sendo, assim, capaz de crescer em ágar Sabouraud sem a necessidade da adição de fonte de ácidos graxos de cadeia longa, o que o diferencia das outras espécies. Forma colônias foscas, com aspecto cremoso e textura macia ou friável. Na micromorfologia apresenta células ovais pequenas $(2 \mu \mathrm{m}-2,5 \mu \mathrm{m} \times 4 \mu \mathrm{m}-5 \mu \mathrm{m})$. Os brotos, que são os maiores entre todas as espécies, surgem na base larga, onde pode ser observado um colarinho ou cicatriz devido a sucessivos brotamentos. Esta espécie apresenta atividade de catalase positiva. A temperatura ideal para o seu desenvolvimento é de $37^{\circ} \mathrm{C}$, e a máxima de $40^{\circ} \mathrm{Cou} 41^{\circ} \mathrm{C}$.

\section{M. sympodialis}

Esta espécie apresenta colônias brilhantes, lisas, planas, com elevação central e textura macia. Na micromorfologia são observadas células ovais ou globosas, com um

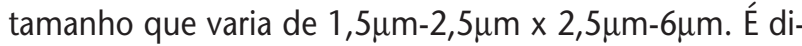
ferenciada de $M$. furfur devido ao seu brotamento simpodial. Apresenta reação de catalase positiva. Não cresce em presença de Tween 20 como única fonte de ácidos graxos, porém cresce em meios suplementados com Tween 40,60 ou 80 em concentrações que variam de $0,1 \%$ a $10 \%$. A temperatura ótima de crescimento é de $37^{\circ} \mathrm{C}$, podendo suportar temperaturas de até $41^{\circ} \mathrm{C}$.

\section{M. globosa}

Apresenta colônias elevadas, dobradas e rugosas, ásperas e quebradiças. Ao exame microscópico apresenta formato esférico que varia de $2,4 \mu \mathrm{m}$ a $8 \mu \mathrm{m}$ de diâmetro, com brotos formados na base estreita. O colarinho ou cicatriz nesta espécie não é tão proeminente como nas demais espécies de Malassezia. Algumas vezes pode ser observada produção de pequenos filamentos próximos ao local de formação do broto, podendo inclusive ocorrer no ponto onde a célula-mãe e a célula-filha se unem. Apresenta reação de catalase positiva. Não cresce em ágar peptonado com glicose acrescido de $0,1 \%$ a $10 \%$ dos diversos tipos de Tween utilizados isoladamente como única fonte de ácidos graxos. Não cresce, ou cresce pouco, em temperatura de $37^{\circ} \mathrm{C}$.

\section{M. obtusa}

Suas colônias são planas e lisas, e apresenta textura mucóide. Na micromorfologia evidenciam-se células ci- 
líndricas grandes com 1,5 $\mathrm{mm}-2 \mu \mathrm{m} \times 4 \mu \mathrm{m}-6 \mu \mathrm{m}$, podendo alcançar mais de $10 \mu \mathrm{m}$. Os brotos são formados na base larga da célula-mãe, enquanto que filamentos podem ser formados sobre qualquer ponto da superfície do micélio. Apresenta reação de catalase positiva. Não cresce em presença de Tween 20, 40, 60 ou 80 que seja utilizado isoladamente como única fonte de ácidos graxos. Geralmente cresce a $37^{\circ} \mathrm{C}$, porém não tolera temperaturas superiores a $38^{\circ} \mathrm{C}$.

\section{M. restricta}

Esta espécie apresenta colônias pouco lisas ou rugosas e textura dura e quebradiça. Ao exame microscópico observam-se células esféricas ou ovais $(1,5 \mu \mathrm{m}-2 \mu \mathrm{m} \times 2,5 \mu \mathrm{m}-4 \mu \mathrm{m})$ e brotos formados na base estreita. É a única espécie a apresentar reação de catalase negativa. Não cresce em presença de $0,1 \%$ a $10 \%$ de Tween $20,40,60$ ou 80 utilizado isoladamente como única fonte de ácidos graxos. Cresce a $37^{\circ} \mathrm{C}$, podendo resistir a temperaturas de até $39^{\circ} \mathrm{C}$.

\section{M. slooffiae}

Apresenta colônias rugosas geralmente com sulcos e textura áspera. Na micromorfologia apresenta células curtas cilíndricas ( $1 \mu \mathrm{m}-2 \mu \mathrm{m} \times 1,5 \mu \mathrm{m}-4 \mu \mathrm{m})$, enquanto que os brotos ocorrem na base larga da célula-mãe. Apresenta reação de catalase positiva, cresce em presença de Tween 40 e 60, porém não em presença de Tween 80 . Algumas amostras não crescem em Tween 20, mesmo em altas concentrações. Cresce a $37^{\circ} \mathrm{C}$, podendo resistir a temperaturas de até $40^{\circ} \mathrm{C}$.

No Quadro é mostrada uma chave taxonômica baseada nos critérios morfofisiológicos para a identificação das espécies de Malassezia (13).
A diferenciação de espécies com base em suas características moleculares pode ser feita através de vários tipos de ensaios, sendo o PFGE (pulsed field gel electrophoresis) e o RAPD (random amplified polymorphic DNA analysis) os mais utilizados $(4,12)$. As duas técnicas utilizadas possuem finalidades diferentes. A primeira é muito útil para a identificação de espécies, embora a segunda forneça informações sobre variações dentro das espécies, como, por exemplo, a identificação de subtipos.

Os dados fornecidos pelo ensaio de PFGE indicaram diferenças entre todas as espécies suficientemente claras e com poucas variações intra-específicas. Exceção a este fato é a espécie $M$. furfur, que possui três perfis de cariótipos claramente distintos: I, II e o subtipo I'.

Quando se utiliza a técnica de RAPD para identificar estes fungos, podem ser observadas variações intra-específicas com a utilização de diversos primers (4). Os autores observaram considerável variação para $M$. furfur, $M$. globosa, M. slooffiae e M. sympodialis. Por outro lado, uma quase total uniformidade de bandas com quase todos os primers padrões utilizados foi observada para as espécies M. restricta, M. pachydermatis e $M$. obtusa.

Outra abordagem descrita inclui os ensaios de seqüenciamento de regiões do seu DNA (14). Neste caso foi utilizado um sistema baseado em PCR com análise subseqüente por endonucleases de amostras pertencentes às espécies de Malassezia, em relação a possível variação no seu DNA ribossomal. Desta forma, embora os autores conseguissem diferenciar cinco de sete espécies reconhecidas, duas delas, $M$. globosa e $M$. restricta, apresentaram padrões eletroforéticos muito parecidos entre si, que foram diferenciados apenas quando os autores utilizaram,

\section{Quadro}

\section{Chave* para a diferenciação morfofisiológica de espécies do gênero Malassezia}

1a. Cresce em ágar peptonado/glicose

1b. Não cresce em ágar peptonado/glicose

2a. Reação de catalase positiva

2b. Reação de catalase negativa

3a. Cresce em ágar peptonado/glicose com 0,5\% de Tween 40 ou 60

3b. Não cresce em ágar peptonado/glicose com 0,5\% de Tween 40 ou 60

4a. Cresce em ágar peptonado/glicose com 0,1\% de Tween 80

4b. Não cresce em ágar peptonado/glicose com 0,1\% de Tween 80

5a. Células longas, cilíndricas, cresce a $37^{\circ} \mathrm{C}$

5b. Células esféricas, geralmente não cresce a $37^{\circ} \mathrm{C}$

6a. Crescimento em ágar peptonado/glicose com 10\% de Tween 20

6b. Não cresce em ágar peptonado/glicose com 10\% de Tween 20
M. pachydermatis

2

3

M. restricta

4

5

6

M. slooffiae

M. obtusa

M. globosa

$M$. furfur

M. sympodialis 
no ensaio, diferentes tipos de primer, obtidos do gene betatubulina.

\section{Patologias associadas às espécies de Malassezia}

Vários estudos têm mostrado que cerca de 50\% a 100\% dos indivíduos clinicamente sadios são portadores de leveduras lipofílicas, principalmente em regiões do corpo ricas em glândulas sebáceas $(19,23,33,37)$. Esta variação observada na freqüência de isolamento pode ser atribuída às diferentes metodologias empregadas pelos autores. Mesmo assim, esta levedura é considerada parte da microbiota normal da pele (37). Para o desenvolvimento e evolução de quadros patológicos associados às espécies do gênero Malassezia é necessário que existam fatores predisponentes no hospedeiro.

Entre as patologias que estão associadas a infecções por espécies do gênero Malassezia podemos citar pitiríase versicolor, foliculite pitirospórica e infecções sistêmicas. Já na dermatite seborréica, na dermatite atópica, na papilomatose confluente reticulada de Gougerot e Carteaud e noutros quadros patológicos, o papel patogênico da Malassezia spp. não está claramente definido, embora seus quadros clínicos possam ser agravados ou desencadeados por esta levedura (37).

Pitiríase versicolor é uma infecção superficial, benigna, freqüentemente recidivante, caracterizada por lesões maculosas, discrômicas e descamativas, que se distribuem em maior freqüência na face, no tronco e nos membros superiores. A maior freqüência dos casos acontece a partir da puberdade, quando ocorrem alterações nos lipídios na superfície da pele decorrentes de modificações hormonais (37). Outro aspecto epidemiológico importante é o de que esta dermatose apresenta maior prevalência em regiões tropicais e subtropicais, onde o clima quente e úmido favorece a colonização da pele pelo fungo, condição esta advinda da hiper-hidratação da camada córnea produzida pela sudorese excessiva (35), o que pode explicar o aumento da sua incidência nos meses de verão.

Outros fatores predispõem a esta infecção: deficiências vitamínicas, desnutrição, doenças crônicas infecciosas como tuberculose, diabete melito, corticoterapia sistêmica, gravidez, pacientes imunodeprimidos e taxas elevadas de cortisol plasmático $(5,30,33)$.

No diagnóstico da pitiríase versicolor, raspados obtidos da lesão são clarificados com potassa e examinados ao microscópio para a procura de massas de leveduras agrupadas e hifas curtas e tortuosas, que são características para esta levedura. Porém, neste caso, a maneira mais correta de expressar o resultado seria indicar a presença de Malassezia sp., porque as várias espécies envolvidas neste quadro patológico apresentam a mesma morfologia neste tipo de exame. Para a identificação das espécies é necessário inicialmente cultivá-las em ágar Sabouraud contendo uma camada fina de óleo de oliva como fonte de ácidos graxos. Posteriormente as mesmas devem ser submetidas aos ensaios morfofisiológicos para a identificação da espécie (13). Em relação a este aspecto, Nakabayashi et al. (23) encontraram as espécies M. globosa (55\%), M.sympodialis (9\%), M. furfur (5\%) e M. slooffiae (5\%) em amostras colhidas da pele de pacientes com pitiríase versicolor, porém com freqüências de isolamento diferentes quando cultivadas em amostras obtidas de quadros de dermatite seborréica e dermatite atópica, ou em pele sadia. Já Gupta et al. (16) utilizaram o meio de LeemingNotman para cultivar Malassezia de pacientes residentes na província de Ontário, no Canadá, e verificaram que $M$. sympodialis, $M$. globosa e $M$. furfur apresentaram uma freqüência de $59,4 \%, 25,2 \%$ e 10,8\%, respectivamente. Crespo et al. (7) estudaram 96 pacientes com pitiríase versicolor e cultivaram as amostras em meio de Dixon modificado. A espécie que apresentou maior freqüência foi $M$. globosa, isolada exclusivamente da parte lesada da pele, seguida de M. sympodialis e M. slooffiae, que foram isoladas de regiões não-afetadas da pele. Os autores concluíram que M. globosa, em sua fase miceliana, foi responsável pelas lesões observadas na pitiríase versicolor.

Foliculite pitirospórica é uma doença infecciosa de distribuição universal, porém ocorre com maior freqüência em climas quentes e úmidos, atingindo principalmente mulheres na faixa de 25 a 35 anos, sendo comuns as recidivas (28). Esta infecção caracteriza-se pela formação de pápulas e pústulas foliculares nos membros superiores, no tronco e no pescoço. A formação das pústulas deve-se à obstrução do folículo piloso por massas de leveduras, o que é agravado pela sua multiplicação. O processo inflamatório ocorre devido à quebra de ácidos graxos livres em triglicérides (37).

Durante a evolução da infecção são observados altos títulos de anticorpos da classe lgG em comparação com os dos pacientes que apresentam quadros de pitiríase versicolor ou de pessoas saudáveis (9). Entretanto não há, ainda, estudos que tenham determinado, em face da nova nomenclatura taxonômica, a espécie ou espécies de Malassezia envolvidas nesta infecção.

Dermatite seborréica é uma dermatose de distribuição universal, e suas principais características são a inflamação e a descamação da pele em áreas ricas em glândulas sebáceas, como face, couro cabeludo e tronco. O grupo 
mais atingido é aquele representado por indivíduos do sexo masculino com idade superior a 40 anos (37). Entretanto recém-nascidos a partir de 8 dias de vida também podem ser acometidos por esta dermatose (34).

A dermatite seborréica caracteriza-se pela formação de lesões eritematodescamativas em couro cabeludo, região retroauricular, mediofacial e mediotorácica, acompanhadas ou não de prurido, sendo associada freqüentemente à colonização por Malassezia (3, 21). Em pacientes HIV-positivos ela é desencadeada de forma súbita e com quadro clínico mais intenso ou grave $(31,32,36)$. Nesta dermatose, as espécies $M$. globosa, M. furfur, $M$. sympodialis e $M$. pachydermatis têm sido isoladas com maior freqüência (23).

Existe uma controvérsia sobre a influência do gênero Malassezia na dermatite atópica. As lesões localizam-se na cabeça, no couro cabeludo e no pescoço, e os pacientes apresentam altos títulos de lgE sérica contra esta levedura (8). Embora em quase $60 \%$ dos pacientes com dermatite atópica possam ser isoladas de sua pele espécies de Malassezia como M. globosa, M. furfur e M. sympodialis, isto corresponde a uma freqüência semelhante à observada em pele de pessoas saudáveis (23).

Descrita por Gougerot e Carteaud em 1927, a papilomatose confluente reticulada ocorre principalmente na região superior do tronco, atingindo principalmente muIheres jovens. Caracteriza-se por pápulas eritematosas ou acastanhadas que evoluem para placas hiperceratinizadas e reticuladas (37). A existência de casos familiares desta dermatose sugere que a mesma possa ser determinada geneticamente (17). Embora sua etiologia ainda seja desconhecida, acredita-se que a ceratinização que ocorre seja resultado da colonização da pele por fungos do gênero Malassezia, embora isto ainda não tenha sido comprovado, já que a utilização de antifúngicos para a erradicação da levedura presente nas lesões nem sempre leva a uma melhoria do quadro clínico $(10,18)$. O seu diagnóstico é firmado nos exames clínico e histopatológico, e, quando se cultiva o material da pele em meios apropriados, obtém-se facilmente o isolamento de Malassezia (37).

Em determinadas situações clínicas, a colonização por Malassezia pode evoluir para um quadro de fungemia. Geralmente ocorre em crianças recém-nascidas que rece- bem alimentação parenteral com suplementação lipídica. Acredita-se que a suplementação lipídica facilite a colonização, pela levedura, do cateter utilizado para infundir os nutrientes, sendo que a remoção do cateter contaminado já é suficiente para limitar a infecção $(6,22)$.

Aractingi et al. (1) descreveram a pustulose neonatal por M. furfur, na qual se observa clinicamente a formação de eritemas, pápulas e pústulas na face, no pescoço e no couro cabeludo de recém-nascido. Acredita-se que o aumento da secreção sebácea favoreça o desenvolvimento do fungo (29). O diagnóstico laboratorial baseia-se no exame microscópico direto do material clínico após clarificação com $\mathrm{KOH}(10 \%$ a $30 \%)$ e isolamento da levedura em meios de cultivo apropriados (27). Embora a doença tenha sido inicialmente associada à infecção por $M$. furfur, nenhum estudo foi realizado até o momento para determinar se outras espécies podem estar associadas a este quadro infeccioso.

\section{Conclusões}

Desde a sua descoberta, o gênero Malassezia passou por várias mudanças taxonômicas, e ainda não foi alcançada uma solução definitiva para a classificação sistemática desta levedura. Considerando correta a classificação atual, o gênero Malassezia apresenta sete espécies: $M$. furfur, M. pachydermatis, M. sympodialis, M. globosa, M.obtusa, M. restricta e M. slooffiae. A importância na diferenciação das espécies de Malassezia não reside apenas no fato da identificação por si só, mas, sim, no fato de que possam existir possíveis diferenças, ainda não determinadas, na sua patogenicidade, visto que já tem sido descrita variação na freqüência das mesmas nas lesões das patologias associadas a esta levedura e na intensidade da agressão por cada uma das espécies, assim como em possíveis diferenças na sua susceptibilidade in vitro a vários antifúngicos $(15,24,25)$. Entretanto o emprego das metodologias supracitadas para a identificação das espécies de Malassezia, em virtude do aumento de custos para sua realização, só deve ser incluído na rotina laboratorial quando novas pesquisas clinicolaboratoriais comprovarem que o mesmo traz algum tipo de benefício na evolução clínica do paciente.

\section{Referências}

I. Aractingi, S. et al. Neonatal pustulosis induced by Malassezia furfur. Ann. Dermatol. Venereol., I I 8(I I): 856-58, 1991.
2. Aspíroz, M.C.; Moreno, L.A. \& Rubio, M.C. Taxonomy of Malassezia furfur: state of art. Rev. Iberoam. Micol., I4(4): |47-9, 1997. 
3. Bergbrant, I.M. \& Faergemann, J. Seborrheic dermatitis and Pityrosporum ovale: a cultural and immunological study. Acta Dermatol. Venereol., 69(4): 332-5, 1989.

4. Boekhout,T.; Kamp, M. \& Guého, E. Molecular typing of Malassezia species with PFGE and RAPD. Med. Mycol., 36(6): 365-72, 1998.

5. Burke, R.C. Tinea versicolor: susceptibility and experimental infection in human beings. J. Invest. Dermatol., 36(4): 389402, 1961 .

6. Chryssanthou, E.; Broberger, U. \& Petrini, B. Malassezia pachydermatis fungaemia in a neonatal intensive care unit. Acta Paediatr., 90(3): 323-7, 2001.

7. Crespo, E.V. et al. Malassezia globosa as the causative agent of pityriasis versicolor. Br.J. Dermatol., 143(4): 799-803, 2000.

8. Devos, S.A. \& Van derValk, P.G. The relevance of skin prick tests for Pityrosporum ovale in patients with head and neck dermatitis. Allergy, 55( I I): 1 056-8, 2000.

9. Faergemann, J. et al. An immunologic and cultural study of Pityrosporum folliculitis. J.Am.Acad. Dermatol., 14(3): 429-33, 1986.

I O. Fuller, L.C. \& Hay, R.J. Confluent and reticulate papillomatosis of Gougerot and Carteaud clearing with minocycline. Clin. Exp. Dermatol., 19(4): 343-5, 1994.

I I. Guého, E.; Midgley, G. \& Guillot, J.The genus Malassezia with description of four new species. Antonie van Leeuwenhoek, 69(4): 337-55, 1996.

12. Guillot, J.\& Guého, E. The diversity of Malassezia yeasts confirmed by rRNA sequence and nuclear DNA comparisons. Antonie van Leeuwenhoek, 67(3): 297-314, 1995.

13. Guillot, J. et al. Identification of Malassezia species: a practical approach. J. Mycol. Méd., 6(2): I03-10, 1996.

14. Gupta,A.K.; Kohli,Y. \& Summerbell, R.C. Molecular differentiation of seven Malassezia species. J. Clin. Microbiol., 38(5): I869$875,2000$.

15. Gupta, A.K. et al. In vitro susceptibility of the seven Malassezia species to ketoconazole, voriconazole, itraconazole and terbinafine. Br J Dermatol., I 42(4): 758-65, 2000

16. Gupta,A.K. et al. Epidemiology of Malassezia yeasts associated with pityriasis versicolor. Med. Mycol., 39(2): 199-206, 2001.

17. Henning, J.P. \& De Wit, R.F. Familial occurrence of confluent and reticulated papillomatosis. Arch. Dermatol., I | 7 ( 12):80910, 1981.

18. Kellett, J.K. \& MacDonald, R.H. Confluent and reticulate papillomatosis. Arch. Dermatol., 12 I (5): 587-8, 1985.

19. Leeming, J.P.; Notman, F.H. \& Holland, K.T. The distribution and ecology of Malassezia furfur and cutaneous bacteria on human skin. J.Appl. Bacteriol., 67(1): 47-52, 1989.

20. Mayser, P. et al. Differentiation of Malassezia species: selectivity of Cremophor EL, castor oil and ricinoleic acid for M. furfur. Br. J. Dermatol., 137(2): 208-13, 1997.

21. McGinley, K.J. et al. Quantitative microbiology of the scalp in non-dandruff, dandruff and seborrheic dermatitis. J. Invest. Dermatol., 64(6): 40I-5, 1975.

22. Mickelsen, P. A. et al. Clinical and microbiological features of infection with Malassezia pachydermatis in high-risk infants. J. Inf. Dis., 157(6): I 163-8, 1988.
23. Nakabayashi, A.; Sei,Y. \& Guillot, J. Identification of Malassezia species isolated from patients with seborrheic dermatitis, atopic dermatitis, pityriasis versicolor and normal subjects, Med. Mycol., 38(5): 337-4I, 2000.

24. Nakamura, Y. et al. Susceptibility testing of Malassezia species using the urea broth microdilution method. Antimicrob Agents Chemother., 44(8): 21 85-6, 2000

25. Pechere, M. et al. Malassezia spp. carriage in patients with seborrheic dermatitis. J. Dermatol., 26(9): 558-6I, 1999.

26. Pier,A.C. et al. Prominent animal mycoses from various regions of the world. Med. Mycol., 38(Suppl. I): 47-58, 2000.

27. Plantin, P. et al. Diagnosing neonatal pustulosis induced by Malassezia furfur. Arch Pediatr., 2(10): 1016, 1995.

28. Potter, B.S.; Burgoon, C.F.\& Johnson,W.C. Pityropsorum folliculitis: report of seven cases and review of the Pytirosporum organism relative to cutaneous disease. Arch. Dermatol. 107(3): 388-91, 1973.

29. Rapenaloro, R. et al. Neonatal Malassezia furfur pustulosis. Arch. Dermatol., 132(2): 190-3, 1996.

30. Roberts, S.O. Pityriasis versicolor: a clinical and mycological investigation. Br. J. Dermatol., 8 I (5): 315-26, 1969.

31. Ross, S.; Richardson, M.D. \& Graybill, J.R. Association between Malassezia furfur colonization and seborrhoeic dermatitis in AIDS patients. Mycoses, 37(9- 10): 367-70, 1994.

32. Schechtman, R.C.; Midgley, G. \& Hay, R.J. HIV disease and Malassezia yeasts: a quantitative study of patients presenting with seborrhoeic dermatitis. Br. J. Dermatol., I 33(5): 694-8, 1995.

33. Schmidt, A. Malassezia furfur: a fungus belonging to the physiological skin flora and its relevance in skin disorders Cutis, 59( I): 21 -4, 1997

34. Souza, C.L.F. et al. Pesquisa da Malassezia furfur em couro cabeludo de lactentes. An. Bras. Dermatol., 7 I (4): 289-92, 1996.

35.Trope, B.M.; Assis, T.L. \& Marques, A.S. Pitiríase versicolor: atualização bibliográfica. An. Bras. Dermatol., 67(4): I 59-66, 1992.

36.Wikler,J.R.; Nieboer, C. \&Willemze, R. Quantitative skin culture of Pityrosporum yeasts in patients seropositive for the human immunodeficiency virus with and without seborrheic dermatitis. J. Am. Acad. Dermatol., 27( I): 37-9, 1992.

37. Zaitz, C.; Ruiz, L.R.B. \& Souza, V.M. Dermatoses associadas às leveduras do gênero Malassezia. An. Bras. Dermatol., 75(2) 129-42, 2000
Endereço para correspondência

Jairo Ivo dos Santos Departamento de Análises Clínicas Centro de Ciências da Saúde Universidade Federal de Santa Catarina Campus Universitário CEP 88040-970 - Florianópolis-SC Tel.: (48) $331-9712$ 